\title{
In vivo and in vitro degradation of glycine/DL-lactic acid copolymers
}

\author{
J. M. Schakenraad, P. Nieuwenhuis, and I. Molenaar \\ University of Groningen, Department of Histology and Centre for Medical Electron Microscopy, \\ Oostersingel 69/1, 9713 EZ Groningen, The Netherlands
}

J. Helder, P. J. Dijkstra, and J. Feijen

University of Twente, Department of Chemical Technology, P.O. Box 217, 7500 AE Enschede, The Netherlands

A series of copolymers of glycine and DLlactic acid with various compositions was synthesized and their in vizo and in vitro degradation behavior was studied. For the in vivo examination, discs of the copolymer films were subcutaneously implanted in rats. The in vitro studies were carried out in phosphate buffer at $\mathrm{pH}=7.4$ and $37^{\circ} \mathrm{C}$. The decrease in molecular weight, the loss of weight, and the tissue reactions of the different copolymers were determined after 2, 5, and 10 weeks. Poly(DLlactic acid) was used as reference material. The in vivo and in vitro degradation behavior of the polymers was comparable. The decrease of molecular weight of the copolymers and poly(DL-lactic acid) in time was similar. The weight loss for copolymers with a higher mole fraction of glycine units started earlier. The copolymer with the highest content of glycine units disappeared completely within 10 weeks both in vivo and in vitro. The poly(DL-lactic acid) implant lost only $25 \%$ weight over the same period. Tissue reactions against all materials started with an acute inflammatory reaction caused by the trauma of implantation, followed by wound-healing processes, ending in a very mild foreign body reaction for the poly(DL-lactic acid) and a more excessive macrophage mediated foreign body reaction for the glycine/ DL-lactic acid copolymers. The tissue reaction was more severe for polymers having a higher rate of degradation.

\section{INTRODUCTION}

The development of biodegradable polymers for use as suture materials, implants, and drug delivery devices has received much attention during the last two decades.$^{1-3}$ Biodegradable polymers are preferably composed of residues normally present in the human body, e.g., lactid acid, ${ }^{4-8}$ glycolic acid, ${ }^{4,5,8,9}$ hydroxy butyric acid ${ }^{10}$ or $\alpha$-amino acids. ${ }^{2,11-13}$

The chemical and biological performance of many of these polymers has already been evaluated. Salthouse and Matlaga ${ }^{14,15}$ have investigated the degradation and tissue reactions of polyglactin 910, a copolymer of L-lactid acid and glycolic acid. These authors showed that the in vivo degradation of this polymer was caused by bulk hydrolysis and that the presence of enzymes did not influence the rate of degradation. The degradation products L-lactic acid and glycolic acid were actively metabolized by the cells sur-

Journal of Biomedical Materials Research, Vol. 23, 1271-1288 (1989)

(C) 1989 John Wiley \& Sons, Inc.

CCC 0021-9304/89/111271-18\$04.00 
rounding the implant. Williams, ${ }^{16}$ however, claimed that the degradation of similar polymers in vitro was accelerated by the presence of enzymes.

In general, tissue reactions which were observed after implantation of a biodegradable material such as polyglactin 910, are characterized by an initial migration of polymorphonuclear and eosinophylic granulocytes toward the site of implantation. If the implant site is not infected, these cells disappear after approximately 3 days. If the material is not immunogenic, lymphocytes will not populate the implantation site. After 1 day macrophages migrate toward the implant and try to envelop the foreign material. Macrophages and, in a later stage, foreign body giant cells will remain in the vicinity of the implanted material until it has completely degraded. ${ }^{10,11,17}$ The severity of tissue reaction, and especially the role of the macrophages, is influenced by the biocompatibility of the polymer, the rate of degradation, and mechanical stresses exerted by the implant. The local mechanical stresses are dependent on the sample shape. ${ }^{17-19}$

Copolymers offer the possibility to obtain materials with a wide range in mechanical properties and rates of degradation. Although several copolymers of $\alpha$-hydroxy acids and copolymers of $\alpha$-amino acids have been prepared and extensively biologically evaluated the work on polydepsipeptides, copolymers of $\alpha$-hydroxy acids and $\alpha$-amino acids has been rather limited. The synthesis and conformational properties of sequential polydepsipeptides were studied by Goodman et al. ${ }^{20,21}$ Kaetsu et al. ${ }^{19,22}$ studied the in vivo degradation of melt pressed films of sequential polydepsipeptides such as poly(Ala-X-Glu(OEt)-Lac) ( $X=$ Gly, Ala and Leu). These films were absorbed within several weeks of implantation (rats). The absorption rate was lower when the side chain of the amino acid $X$ was larger. ${ }^{24} \mathrm{~A}$ systematic study on the degradation mechanism of polydepsipeptides has not yet been performed.

We have prepared copolymers of glycine and DL-lactic acid with different compositions. ${ }^{23}$ Discs of these copolymers were subcutaneously implanted in rats and the tissue reaction and rate of degradation were studied as a function of time. Poly(DL-Lactic acid) (PDLA) was used as reference material. The results of the in vivo degradation were compared with those obtained in vitro.

\section{MATERIALS AND METHODS}

\section{Synthesis and characterization}

The copolymers used in this study were synthesized by ring-opening polymerization of cyclo(glycine-DL-lactic acid) (monomer 1) and DL-dilactide (monomer 2) using stannous octoate [tin(II) bis(2-ethylhexanoate)] as initiator (Fig. 1). Mole fractions of DL-dilactide in the feed of 0.60 and 0.80 (sample codes 60 and 80 ) were applied. The copolymerization reaction was performed as described previously by Helder et al. ${ }^{23}$ The poly(DL-lactic 
<smiles>CC1OC(=O)CNC1=O</smiles>

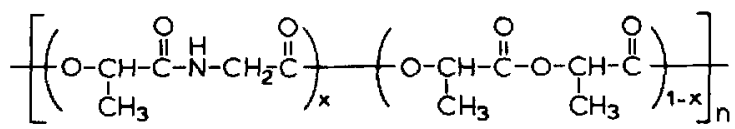

Figure 1. Synthesis of glycine/DL-lactic acid copolymers. $x$ represents the mole fraction of monomer 1.

acid) (sample code 100) was a gift from CCA biochem, Gorinchem, The Netherlands.

The copolymers were characterized with respect to molar composition, apparent number average, and weight average molecular weights $\left(M_{n, \text { app }}\right.$ and $\left.M_{w, a p p}\right)$ and glass transition temperatures.

\section{Molar composition}

The molar composition of the copolymers was determined by ${ }^{1} \mathrm{H}-\mathrm{NMR}$ spectroscopy. The spectra were recorded on a Nicolet $200 \mathrm{MHz}$ NMR apparatus using $\mathrm{CDCl}_{3}$ as a solvent and tetramethylsilane (TMS) as an internal reference. The composition was calculated from the methylene and methine proton integrations. The methylene proton signal at $4.0 \mathrm{ppm}$ (Fig. 2) in the spectrum of the copolymer is characteristic of the glycine moiety from the (Gly-DL-Lac) unit (1). The methine proton signal at $5.1 \mathrm{ppm}$ results from both monomeric units ( 1 and 2 ).

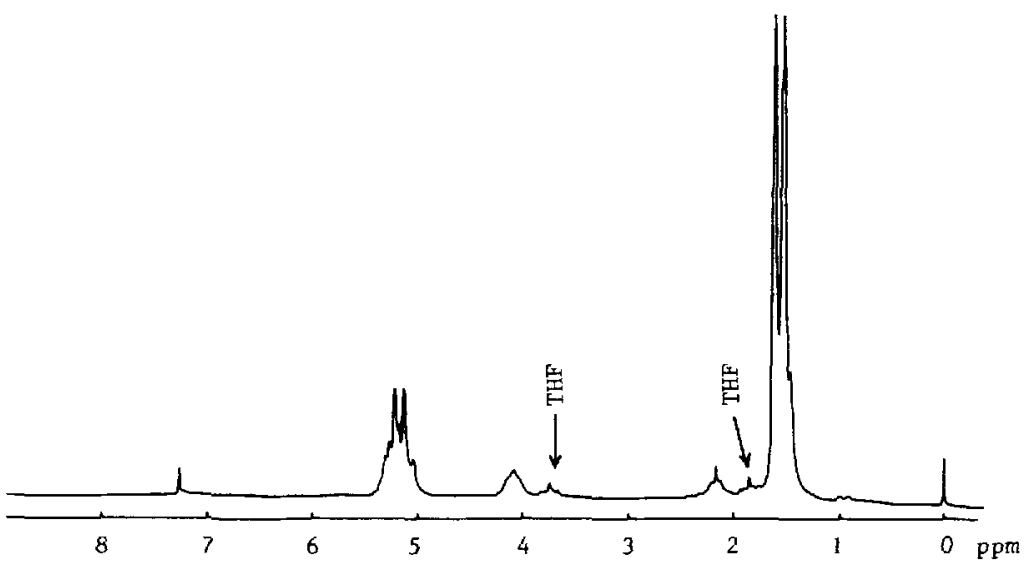

Figure 2. ${ }^{1} \mathrm{H}$ NMR spectrum $\left(\mathrm{CDCl}_{3}\right)$ of copolymer 60 . 


\section{Molecular weights}

High performance gel permeation chomatography (GPC) was used to determine the molecular weight distributions, $\left(M_{n, a p p}\right), M_{w, a p p}$ of the (co)polymer samples. The GPC unit consisted of a Waters model $6000 \mathrm{~A}$ pump and a Waters U6K injector, four Waters $\mu$ Styragel $\left(10^{5}, 10^{4}, 10^{3}\right.$, and $500 \AA$ in pore size) columns in series and a Waters R401 differential refractometer. Elution was performed at $25^{\circ} \mathrm{C}$ with a flow rate of $2.0 \mathrm{~mL} / \mathrm{min}$ using tetrahydrofuran (THF) as eluent. The columns were calibrated with polystyrene standards having a narrow molecular weight distribution.

To obtain a better estimation of the real values of the initial molecular weights of the copolymers we have also determined $M_{n, \text { calc }}$ values. The $M_{n, \text { calc }}$ value of, e.g., copolymer 60 was obtained by multiplying the $M_{n, a p p}$ value of copolymer 60 with the ratio $M_{n^{*}} / M_{n, \text { app }}$ determined for a copolymer with the same composition but a different molecular weight. The $M_{n^{*}}$ value was measured by membrane osmometry and the $M_{n, a p p^{*}}$ value was measured by GPC.

It has to be realized that the $M_{\mathrm{r}, \mathrm{app}}$ values measured in principle depend on the composition of the molecules. During degradation the molecular weight of the molecules is changing and also their chemical compositions may change. Therefore the $M_{\mathrm{n} \text {,app }}$ data may only be applied to compare the in vitro and in vivo degradation of the same polymer sample.

\section{Glass transition temperatures}

Glass transition temperatures $\left(T_{\mathrm{g}}\right)$ were measured with differential scanning calorimetry (DSC) using a DuPont 990 thermal analyzer and cell base. Prior to the measurements the samples $(3-4 \mathrm{mg})$ were preheated at 130 $150^{\circ} \mathrm{C}$ for $15 \mathrm{~min}$ and then cooled to room temperature. A heating rate of $10^{\circ} \mathrm{C} / \mathrm{min}$ and a sensitivity of $0.2 \mathrm{mcal} / \mathrm{s}$ were used. The $T_{\mathrm{g}}$ values were taken as the intersection of the extrapolation of the baseline with the extrapolation of the inflexion.

\section{Preparation of polymer discs}

Films were made by casting solutions of the (co)polymers in THF $(15 \% \mathrm{w} / \mathrm{v})$ onto glass surfaces (petri dishes), which were previously treated with a $30 \% \mathrm{v} / \mathrm{v}$ solution of dichlorodimethylsilane in toluene. The solvent was slowly removed by evaporation in air at room temperature for at least 3 days, and subsequently at $40^{\circ} \mathrm{C}$ for 2 days at reduced pressure. The films were then immersed in demineralized water for $2 \mathrm{~h}$ to exchange residual solvent. After removal from the water the films were dried over $\mathrm{P}_{2} \mathrm{O}_{5}$ in vacuo for $18 \mathrm{~h}$. The white films were cut into 8 -mm-diameter discs which were dried under vacuum at $40^{\circ} \mathrm{C}$ for $18 \mathrm{~h}$. The ${ }^{1} \mathrm{H}$ NMR spectra of the (co)polymers showed that traces of THF were present (Fig. 2). In order to re- 
move the remaining THF the discs were immersed in $0.04 \mathrm{M}$ phosphate buffer $(\mathrm{pH}=7.2)$ at $4^{\circ} \mathrm{C}$ for $24 \mathrm{~h}$. The buffer was exchanged every $4 \mathrm{~h}$. After drying for $16 \mathrm{~h}$ over $\mathrm{P}_{2} \mathrm{O}_{5}$ in vacuo the ${ }^{1} \mathrm{H}$ NMR spectra $\left(\mathrm{CDCl}_{3}\right)$ of the (co)polymers showed no THF present.

\section{Characterization of the discs}

The initial weight of the discs was $34.7 \pm 0.8 \mathrm{mg}$ for copolymer 60 , $34.4 \pm 0.9 \mathrm{mg}$ for copolymer 80 and $20.4 \pm 3 \mathrm{mg}$ for polymer 100 . The discs have an average thickness of $1.0 \pm 0.1 \mathrm{~mm}$. The discs were also examined by scanning electron microscopy (SEM) with a JEOL JSM $35 \mathrm{CF}$ scanning electron microscope. The samples were coated with a charge conducting layer of gold using a Balzer sputter unit. Contact angles of water and $\alpha$-bromonaphthalene were determined by the sessile drop method as described by Busscher et al. ${ }^{24}$

\section{In vitro degradation}

The in vitro degradation studies were performed at $37^{\circ} \mathrm{C}$ in $0.1 \mathrm{M}$ $\mathrm{Na}_{2} \mathrm{HPO}_{4} / \mathrm{KH}_{2} \mathrm{PO}_{4}$ buffer $\mathrm{pH}=7.4$ containing $0.03 \mathrm{w} / \mathrm{v} \% \mathrm{NaN}_{3}$. The degradation was followed by determining the apparent molecular weight and weight at $0,2,5$, and 10 weeks immersion in the buffer solution $(n=3)$.

\section{In vivo degradation}

After desinfection with $70 \%$ ethanol the discs were subcutaneously implanted in female $\mathrm{AO} / \mathrm{BN}$ rats 6 months of age and weighing approximately $200 \mathrm{~g}$. The wound was closed with one or two sutures (Dexon 4-0). Two discs were implanted on the back of each rat, one for determination of residual weight and $M_{n, a p p}$, and one for studying the tissue reactions. For each copolymer and implantation time, one rat was used. After 2, 5, or 10 weeks the discs were removed. Discs for determination of residual weight and $M_{n, \text { app }}$ were carefully trimmed free of all surrounding tissue. Discs for determination of tissue reactions were removed with excess surrounding tissue and immediately fixed in $2 \%$ glutaraldehyde in $0.1 \mathrm{M}$ phosphate buffer $(\mathrm{pH}=7.2)$ at $4^{\circ} \mathrm{C}$ for at least $12 \mathrm{~h}$.

\section{Determination of weight}

After removal from the buffer solution or from the implant site the discs were dried in a desiccator in vacuo over $\mathrm{P}_{2} \mathrm{O}_{5}$ for $24 \mathrm{~h}$. The weight loss of 
each disc was determined by comparing the dry weight of the degraded (co)polymer with the initial weight.

\section{Tissues reactions}

Specimens for studying tissue reactions were fixed in $2 \%$ glutaraldehyde and prepared for light microscopy by embedding in glycol methacrylate (GMA) as described in detail by Gerrits et al. ${ }^{25}$ Samples were dehydrated in ethanol and subsequently pretreated for $2 \mathrm{~h}$ with $50 \%$ monomer solution in ethanol. The monomer solution consisted of $90 \mathrm{v} / \mathrm{v} \%$ 2-hydroxyethyl methacrylate, $10 \mathrm{v} / \mathrm{v} \%$ 2-butoxyethanol and $0.5 \mathrm{v} / \mathrm{v} \%$ tribenzoylperoxide (initiator). Subsequently, the samples were treated with $100 \%$ monomer solution for $48 \mathrm{~h}$. Afterward, the samples were polymerized for $40 \mathrm{~min}$ at room temperature by adding an accelerator solution (final concentration $3 \mathrm{v} / \mathrm{v} \%$ ). The accelerator solution consisted of $6 \mathrm{v} / \mathrm{v} \% \mathrm{~N}, \mathrm{~N}$-dimethylaniline and $94 \mathrm{v} / \mathrm{v} \%$ polyethylene glycol. After polymerization, $2-\mu \mathrm{m}$ microtome sections were cut and stained with toluidene blue and alkaline fuchsine as described by Blaauw et al. ${ }^{26}$

\section{RESULTS}

The molar compositions, initial molecular weights, and glass transition temperatures of the (co)polymers are listed in Table I. The calculated values of $M_{n}$ give a better estimation of the real molecular weight values. The data show that the initial molecular weight of copolymer 80 was somewhat higher than those of copolymer 60 and polymer 100 and that the molecular weights are in the same order of magnitude.

The hydrophilicity of the (co)polymer films was determined using contact angle measurements. The contact angles of water and $\alpha$-bromonaphthalene were $70^{\circ}$ and $30^{\circ}$ for copolymer $60,75^{\circ}$ and $25^{\circ}$ for copolymer 80 and $80^{\circ}$ and $20^{\circ}$ for polymer 100 , respectively. The surface free energies as determined by the procedure of Busscher et al. are in the range of $54-63 \mathrm{erg} / \mathrm{cm}^{2}$.

TABLE I

Characterization of (Co)polymers Used for the Degradation Studies

\begin{tabular}{cccccc}
\hline $\begin{array}{c}\text { Sample } \\
\text { Code }\end{array}$ & $\begin{array}{c}\text { Mole Fraction DL-Dilactide } \\
\text { Units in the Copolymer }\end{array}$ & $\begin{array}{c}M_{\text {n, app }} \text { a } \\
\left(\times 10^{-4}\right)\end{array}$ & $\begin{array}{c}M_{\mathrm{n}, \text { calc }} \text { b } \\
\left(\times 10^{-4}\right)\end{array}$ & $\begin{array}{c}M_{\text {w, app }} \text { a } \\
\left(\times 10^{-4}\right)\end{array}$ & $\begin{array}{c}T_{\mathrm{g}}^{\mathrm{c}} \\
\left({ }^{\circ} \mathrm{C}\right)\end{array}$ \\
\hline 60 & $0.64 \pm 0.03$ & 0.6 & 1.5 & 1.8 & 69 \\
80 & $0.82 \pm 0.03$ & 1.9 & 3.3 & 3.9 & 61 \\
100 & 1.00 & 2.4 & 2.0 & 5.2 & 54 \\
\hline
\end{tabular}

${ }^{a}$ Apparent molecular weights were measured by GPC.

${ }^{b}$ Calculated $M_{n}$ values (see Materials and Methods).

${ }^{\mathrm{c}}$ Glass transition temperatures were measured by DSC. 
Scanning electron micrographs show that the discs have a dense inner structure and pores of 5-10 $\mu \mathrm{m}$ near the surfaces (Fig. 3). The discs have a dense skin with an occasional cavity smaller than $1 \mu \mathrm{m}$ (Fig. 4).

Figures 4-6 show $M_{n, \text { app }}$ and the residual weight of the discs as a function of time for both the in vivo and in vitro studies. Copolymer 60 disappeared the fastest and in vitro a weight loss of $97 \%$ within 10 weeks was observed (Fig. 5). Copolymer 80 lost $70 \%$ of its weight within 10 weeks (Fig. 6), whereas for polymer 100 a weight loss of $80 \%$ over the same period was observed (Fig. 7). The $M_{n, a p p}$ values of the (co)polymers immediately decreased from the onset of the experiment.

After 2 weeks the implanted (co)polymers showed a decrease in $M_{n, \text { app }}$ of about $50 \%$. The degradation behavior in vivo was similar to that in vitro. In vivo the discs of copolymer 60 were almost completely absorbed after 10 weeks. Discs of copolymer 80 and polymer 100 lost only $30 \%$ of their original weight over that same period. The rate of weight loss in vitro was higher than that in vivo.

The morphological appearance of all discs had hardly changed after 2 weeks implantation, both macroscopically and microscopically (Fig. 8). After 5 weeks, the thickness of the discs of copolymers 60 and 80 had increased three times. The diameters were slightly diminished. Tissue had entered the polymer matrix and the discs started to desintegrate (Fig. 9). After 10 weeks of implantation the discs of copolymer 60 had almost completely disappeared (Figs. 10 and 11). Discs of copolymer 80 were spherical with a diameter of approximately $5 \mathrm{~mm}$. The discs of polymer 100 also showed signs of degradation, but still had their original appearance.

After 2 weeks (Fig. 8) macrophages had already penetrated the implants of copolymer 60 . Approximately five layers of macrophages and an occasional giant cell surrounded the implant. On top of these layers approximately 10 layers of fibroblasts encapsulate the implant. After 5 weeks a large number of macrophages and giant cells were still observed and the implants were partly degraded (Fig. 9). Extensive tissue infiltration into the discs was seen. Blood vessels grow toward and into the implant. After 10 weeks, hardly any polymer material was left (Fig. 10). Macrophage and giant cell activity were still observed. Many polymer fragments were seen inside macrophages and giant cells (Fig. 11). Macrophages containing polymer debris were occasionally observed outside the original implant site indicating removal of debris-laden macrophages.

Copolymer 80 (Fig. 12) showed a similar macrophage mediated foreign body reaction as copolymer 60 . After 2 weeks hardly any tissue infiltration into the implant was present. Approximately eight layers of macrophages and five layers of fibroblasts were surrounding the implant. After 5 weeks some tissue infiltration with macrophages and giant cells was seen (Fig. 13). After 10 weeks, extensive tissue infiltration was observed with far fewer phagocytes as compared to copolymer 60 .

Polymer 100 hardly showed any visible degradation and a minor tissue reaction. Even after 10 weeks only a minor phagocytic activity was observed around implants of this polymer (Fig. 14). 


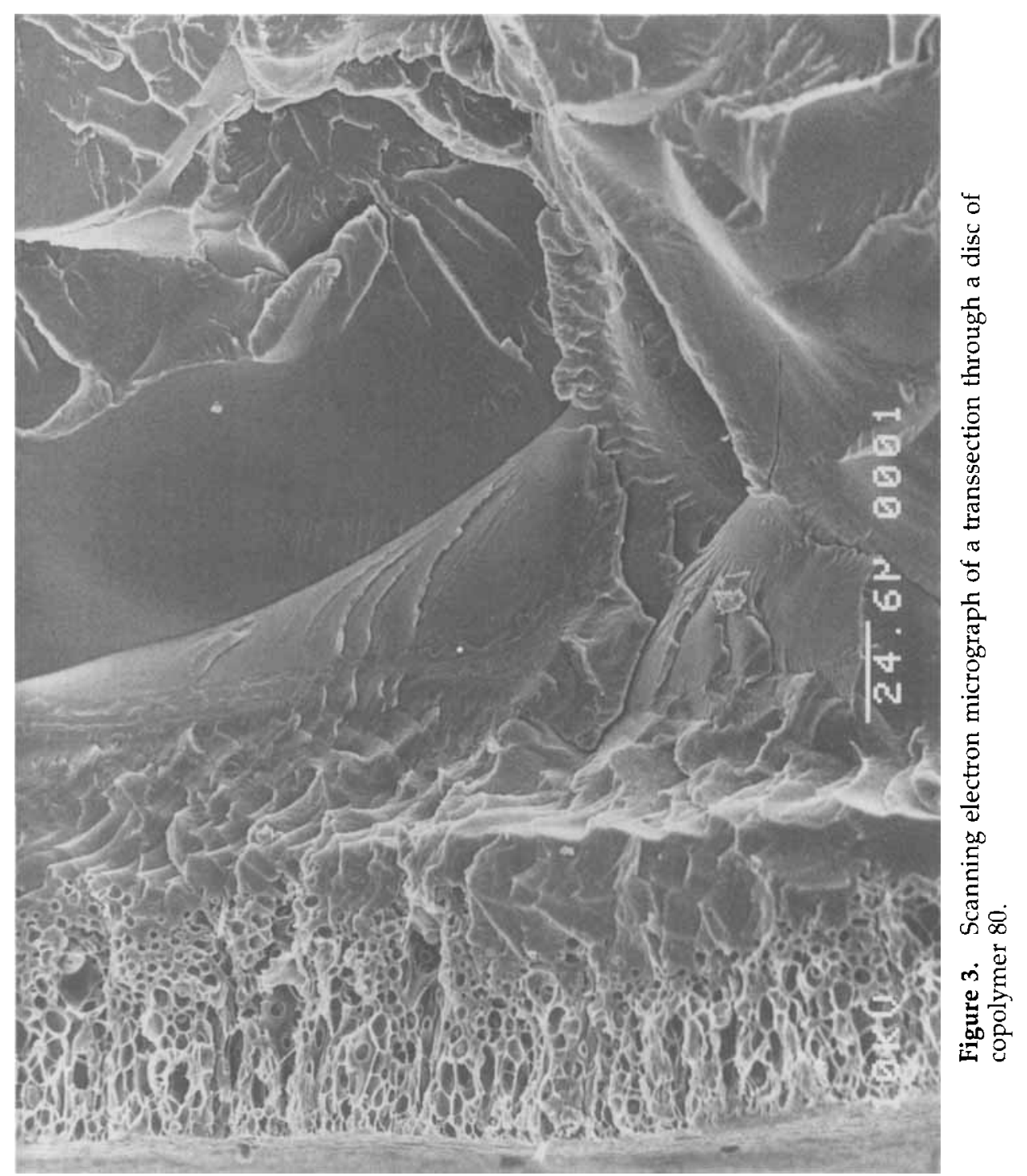




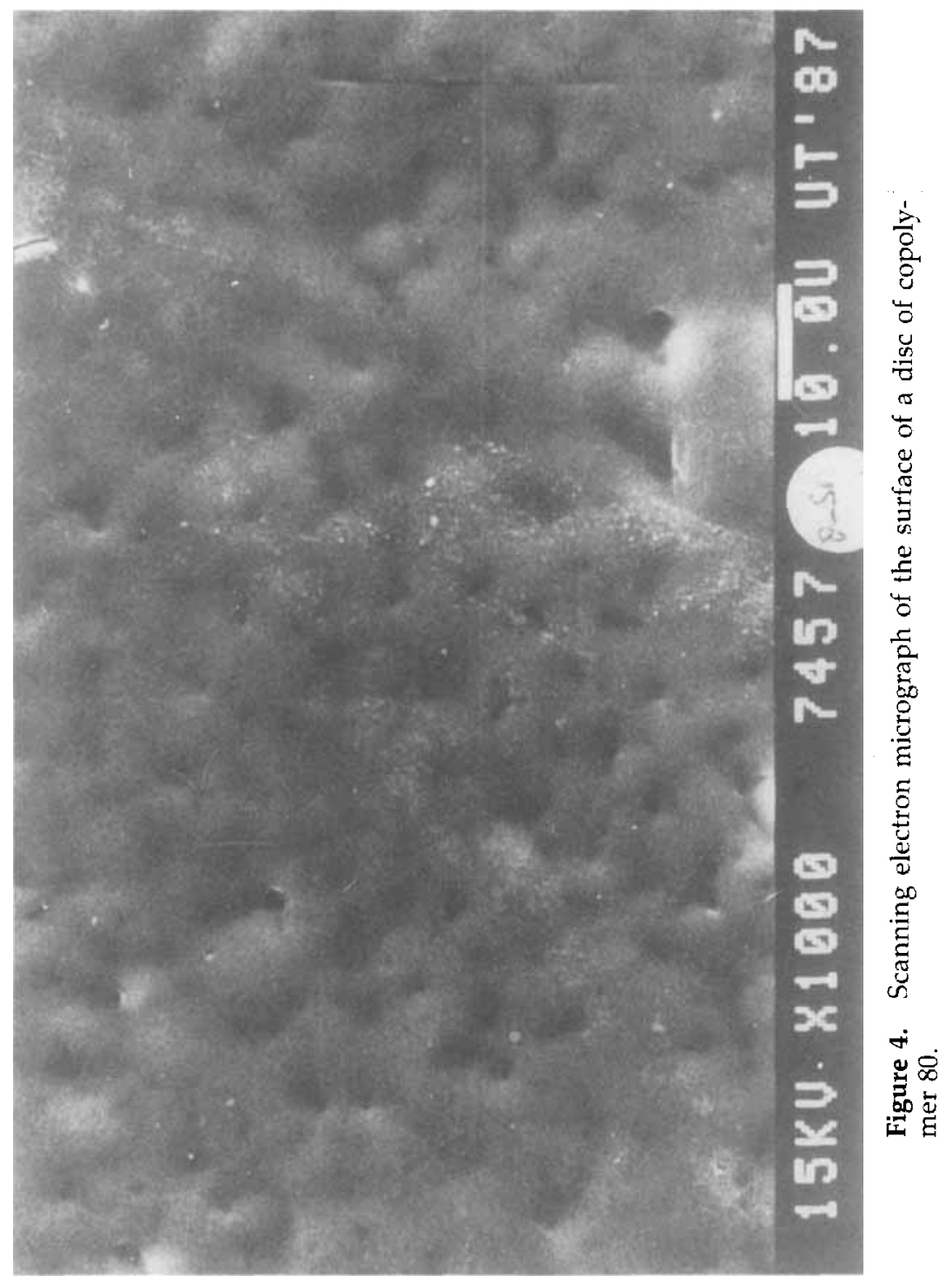




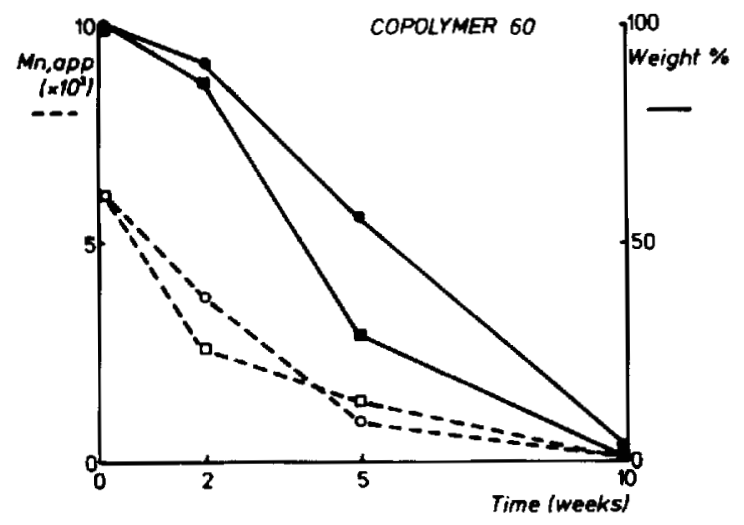

Figure 5. Changes in $M_{n \text {,app }}[$ in vitro( $\square)$ and in vivo(o)] and residual weight $(\%)$ in vitro (D) and in viro (๑)] of copolymer 60 .

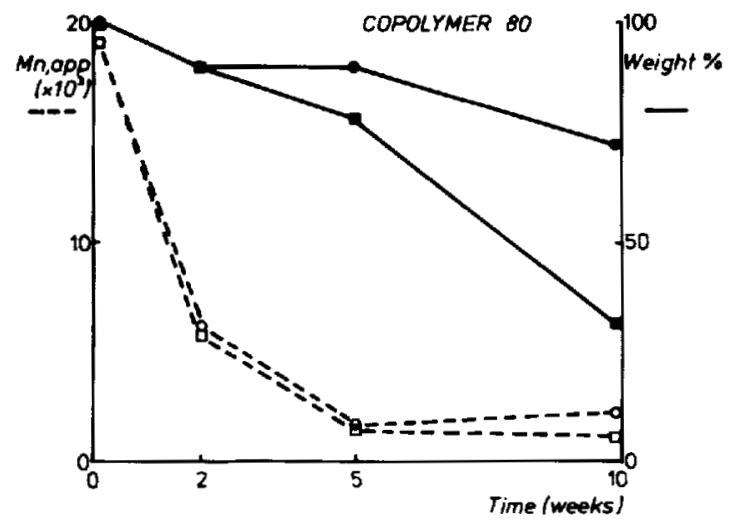

Figure 6. Changes in $M_{n, \text { app }}$ [in vitro (J) and in vivo (0)] and residual weight (\%) [in vitro (a) and in vivo $(\bullet)$ ] of copolymer 80.

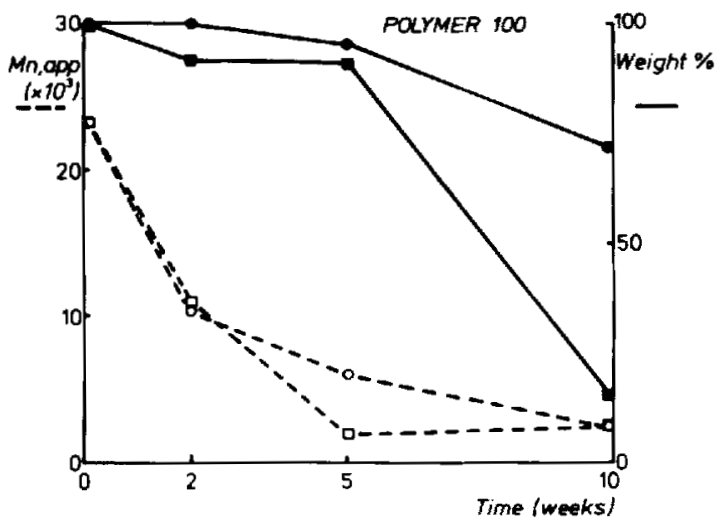

Figure 7. Changes in $M_{\mathrm{n} \text {,app }}$ [in vitro ( $\square$ ) and in vivo (o)] and residual weight

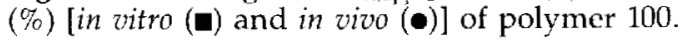




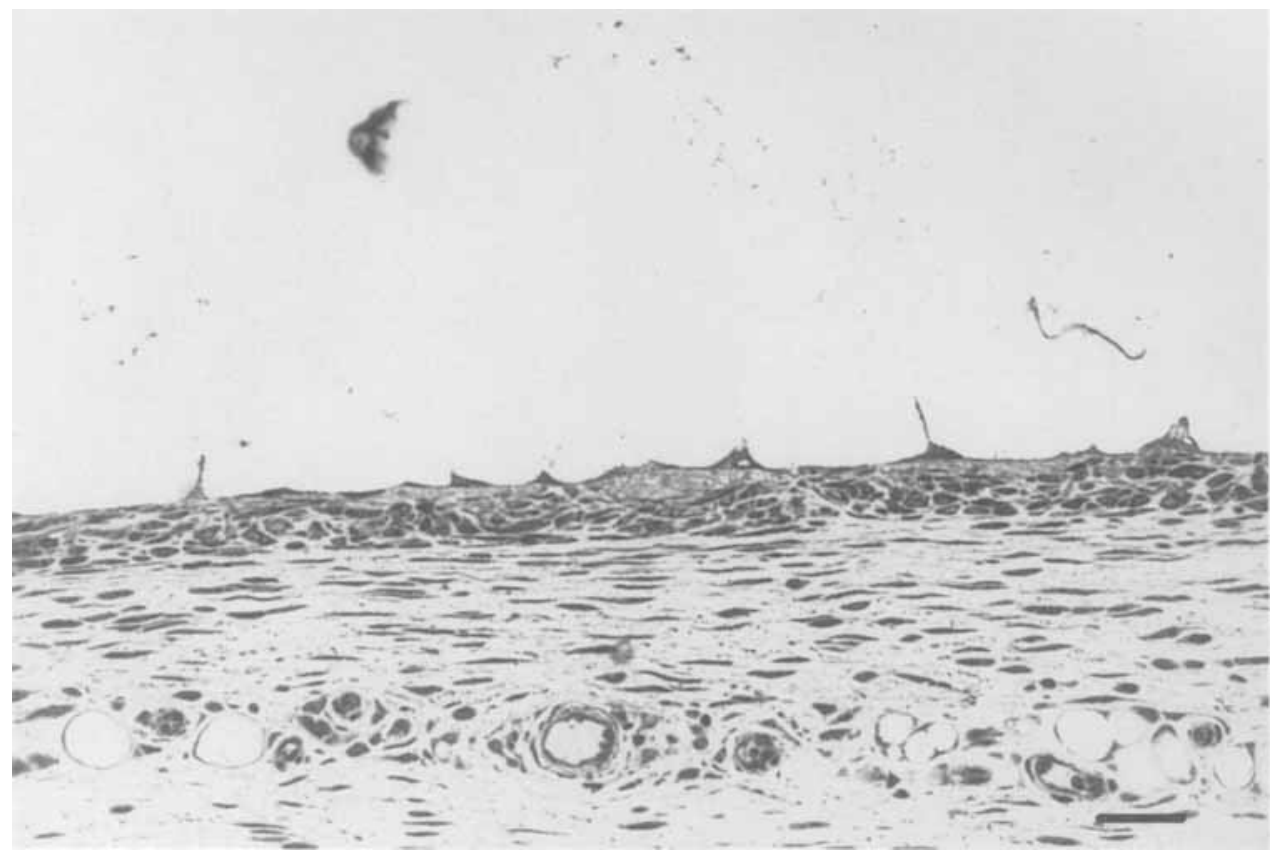

Figure 8. Copolymer 60 after 2 weeks implantation. Approximately five layers of macrophages and a sheet of fibroblasts surrounded the implant. Blood vessels close to the implant can be observed. The bar represents $64 \mu \mathrm{m}$.

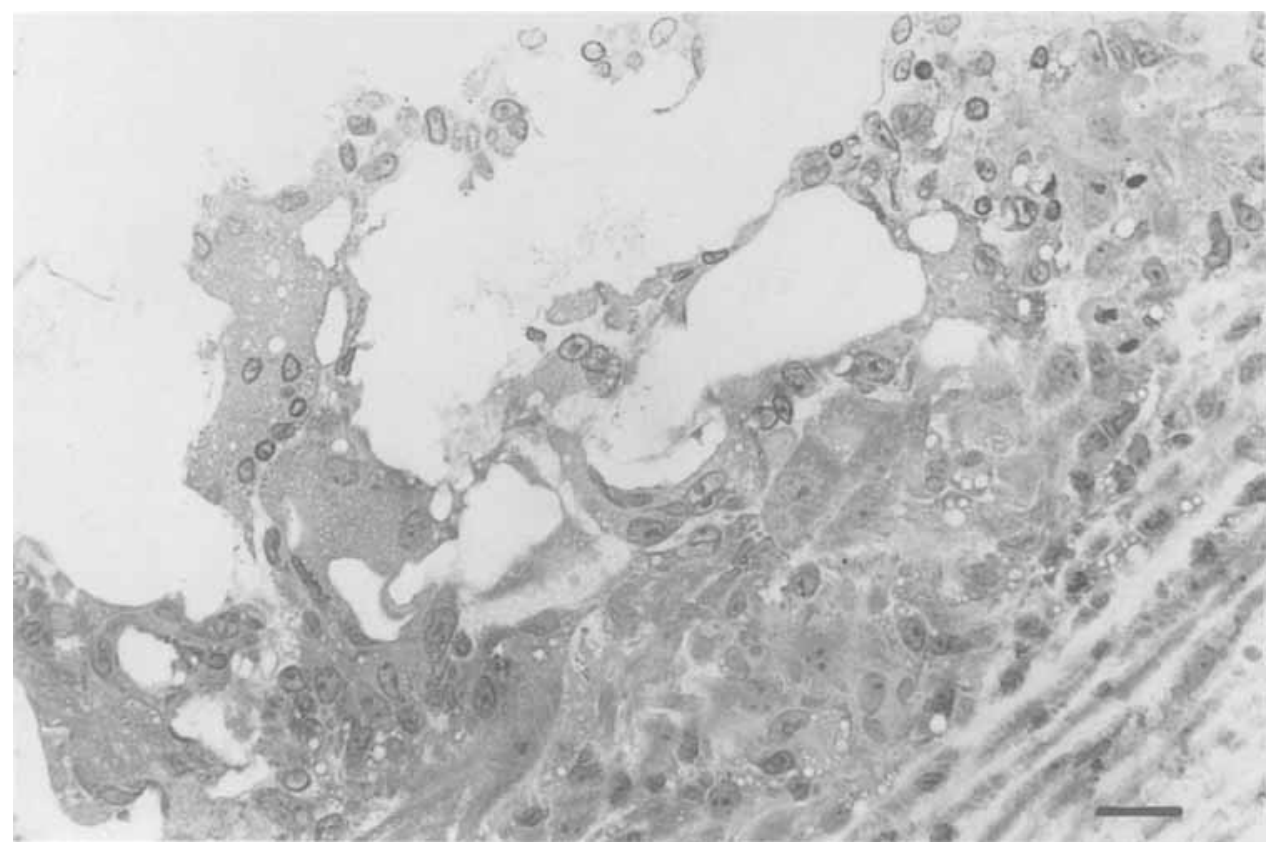

Figure 9. Copolymer 60 after 5 weeks implantation. Macrophages have infiltrated in the desintegrating polymer matrix. Giant cells can be observed. The bar represents $100 \mu \mathrm{m}$. 


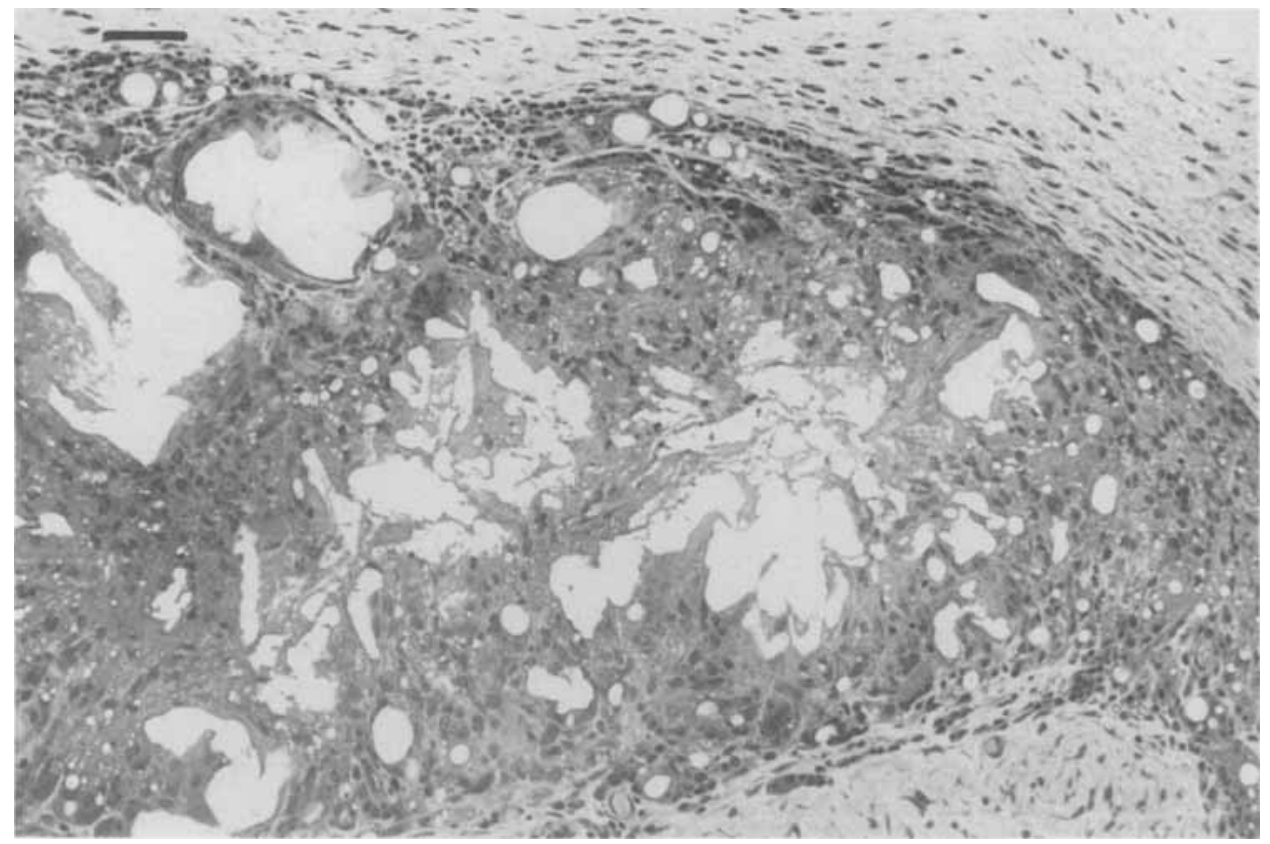

Figure 10. Copolymer 60 after 10 weeks implantation. Only small fragments remain. The bar represents $40 \mu \mathrm{m}$.

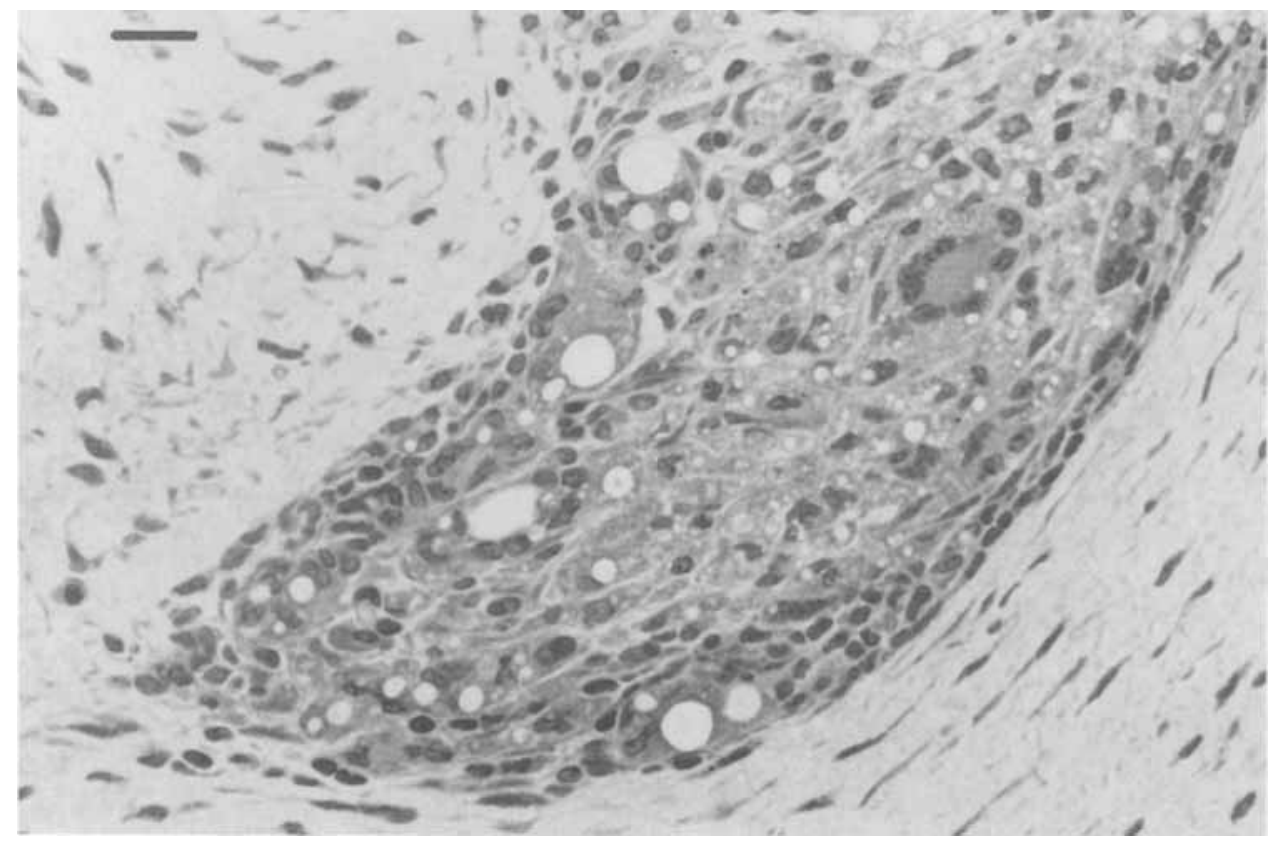

Figure 11. Copolymer 60 after 10 weeks implantation. Polymer debris is engulfed by single macrophages or by giant cells. The bar represents $100 \mu \mathrm{m}$. 


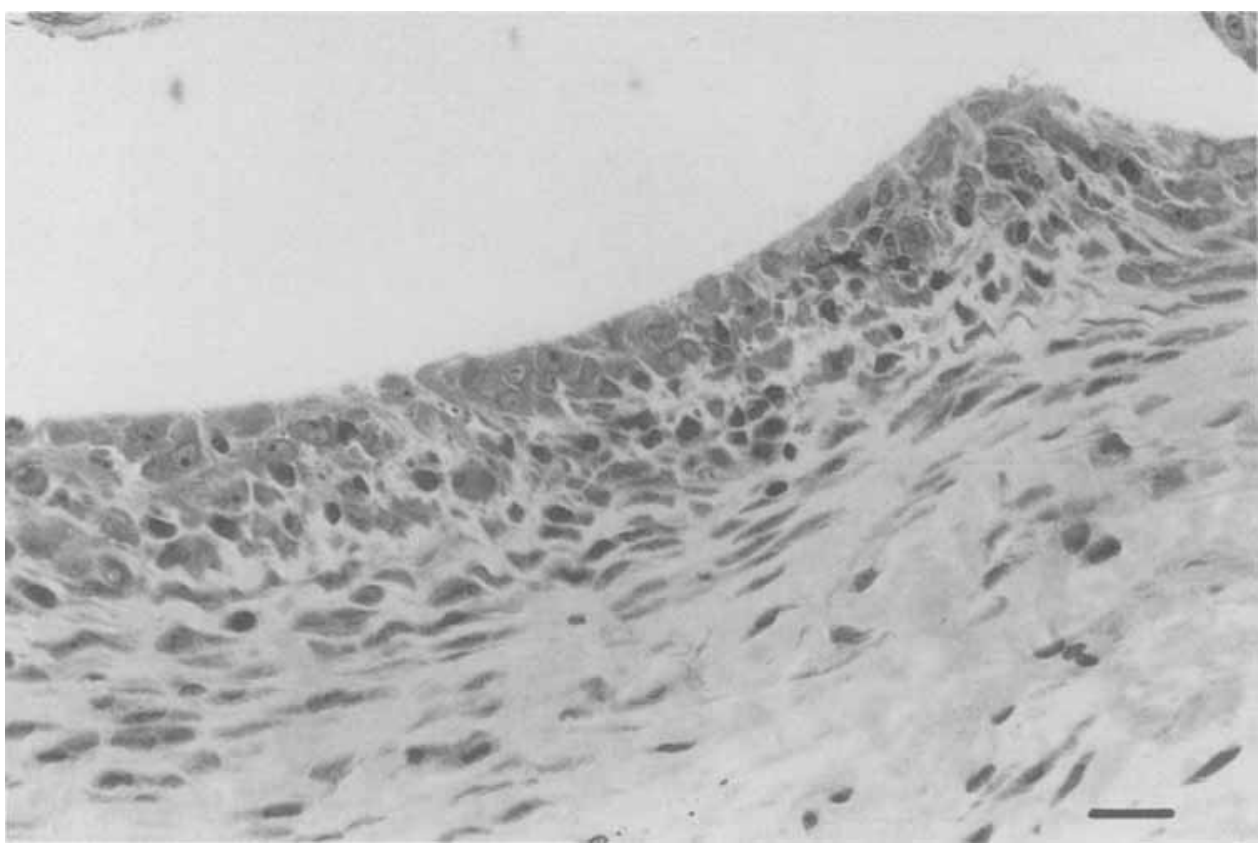

Figure 12. Copolymer 80 after 2 weeks implantation. Hardly any infiltration into the implant can be observed. The bar represents $100 \mu \mathrm{m}$.

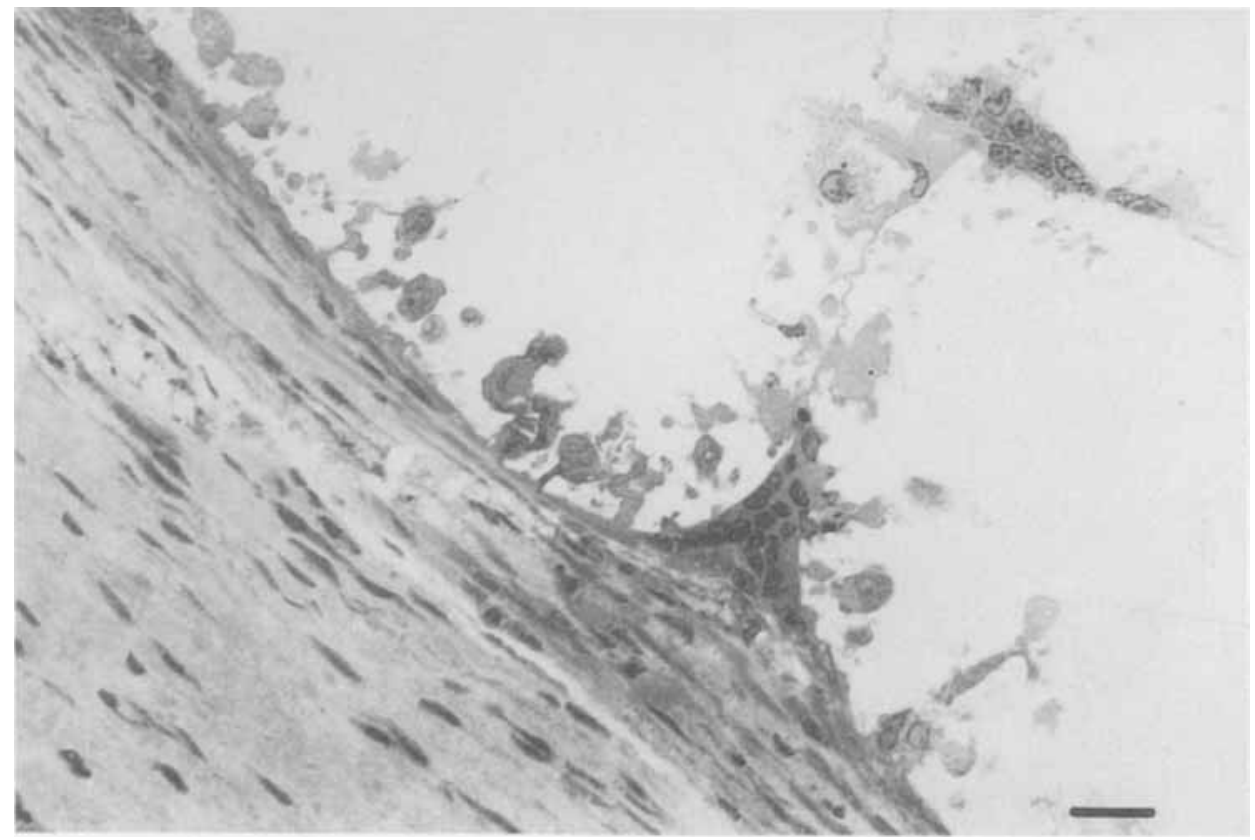

Figure 13. Copolymer 80 after 5 weeks implantation. The number of macrophages and giant cells is far less than with copolymer 60. Only small infiltrations into the implant are observed. The bar represents $100 \mu \mathrm{m}$. 


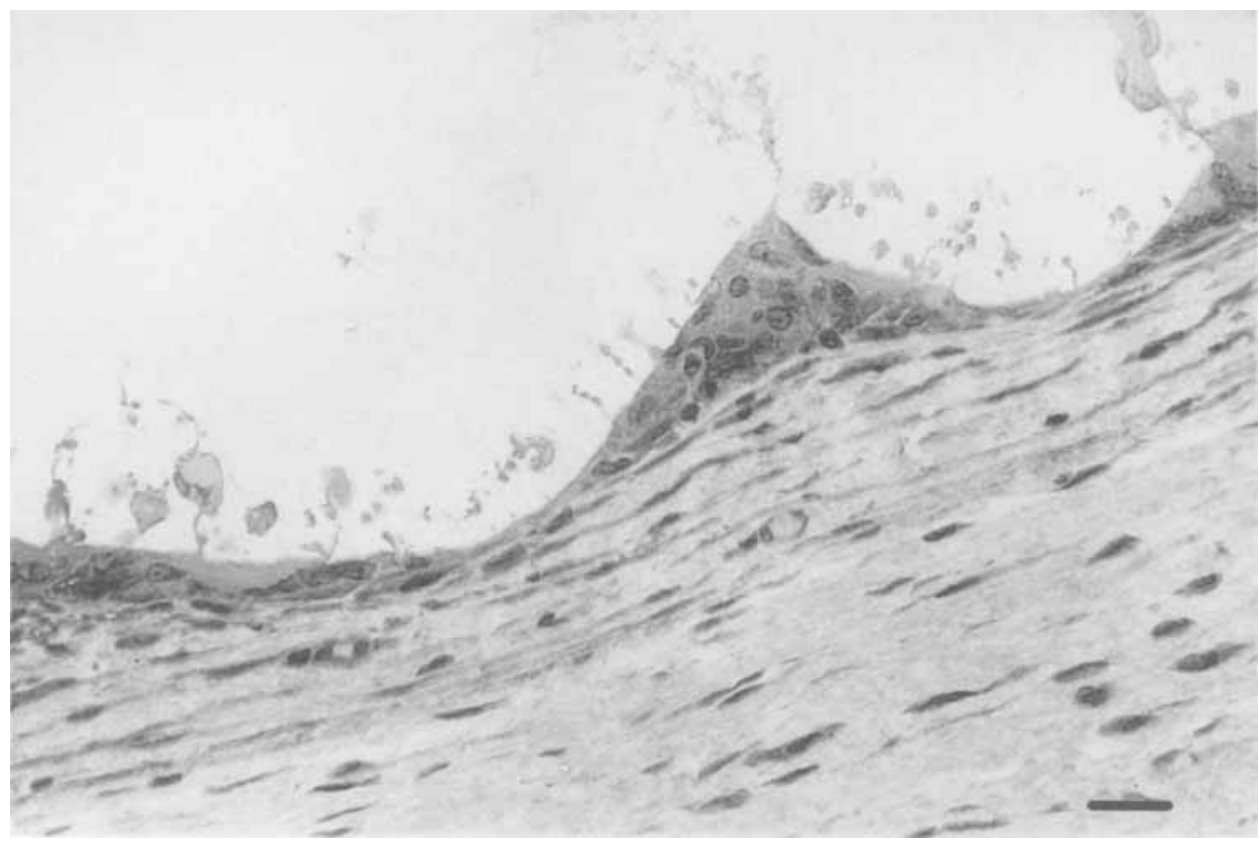

Figure 14. Polymer 100 after 10 weeks implantation. Only minor giant cell and macrophage activity is observed. The sheet of fibroblast tissue around the implant is thinner than around copolymers 60 and 80 . The bar represents $100 \mu \mathrm{m}$.

\section{DISCUSSION}

The glycine/DL-lactic acid copolymers were synthesized by a ring-opening polymerization reaction of monomers 1 and 2 (Fig. 1). Previous studies showed that DL-dilactide (monomer 2 ) was preferentially incorporated into the copolymer. The discs prepared from the (co)polymers were studied by scanning electron microscopy and contact angle measurements. The scanning pictures (Figs. 3 and 4) show that initially the discs have a dense inner structure, pores near the surface and a dense skin. Contact angle measurements demonstrated that the surface free energy of the polymers increased with increasing glycine content, which corresponds with the more hydrophylic character of glycine residues as compared to lactic acid residues.

In a recent paper by our group ${ }^{27}$ an extensive in vitro degradation study was described, using glycine/DL-lactic acid copolymers with mole fractions of $0.50,0.60,0.70,0.75,0.80$, and 0.90 DL-dilactide units. From the decrease of the molecular weight as a function of time it was concluded that the degradation mechanism can be described as bulk hydrolysis of the ester bonds, autocatalyzed by the generated carboxylic end groups. ${ }^{27,28}$ It was further observed ${ }^{27}$ that the rate of ester bond scission was comparable for the copolymers. From the weight loss profiles it was concluded that copolymers with a higher percentage of glycine units dissolved earlier, which could be ascribed to a higher solubility of the low-molecular-weight fragments rich in 
glycine units. The in vitro results described in this paper correspond to the results mentioned above. ${ }^{27}$

The decrease of the apparent molecular weight as a function of time was comparable in vitro and in vivo for the same copolymer (also see the remarks given in the section Molecular weights). The data suggest that the degradation mechanism in vivo is the same as observed in vitro: bulk hydrolysis of ester bonds. This indicates that the enzymatic degradation, as was determined in the in vitro degradation of poly(L-lactic acid), ${ }^{16}$ does not play an important role.

The rate of decrease of both molecular weight and weight loss were somewhat higher in vitro than in vivo. This phenomenon was also observed by Pitt et al. ${ }^{29}$ for the degradation of poly(DL-lactic acid), poly( $\varepsilon$-caprolactone) and their copolymers. This phenomenon can possibly be explained by the formation of a tissue capsule around the implant causing an accumulation of degradation products. Furthermore the protein-containing environment may cause a lower solubility of the copolymers.

The in vivo weight loss started earlier for copolymers with a higher glycine content, which corresponds to the in vitro observations. Biodegradation of the glycine/DL-lactic acid copolymers can be described by two stages. First the molecular weight decreases as a result of the ester bond scission described. This is illustrated by the instantaneous decrease of $M_{\mathrm{w} \text {,app }}$ and $M_{\text {n,app }}$ as shown in Figures 4-6. As soon as the fragments are small enough to become soluble, weight loss is observed. The time at which weight loss and consequently dissolution of the low molecular weight fragments occurs depends on the percentage of glycine units in the copolymer, and the initial molecular weight of the (co)polymer.

The tissue reactions observed reflect a general wound-healing reaction followed by a phase of phagocytosis and removal of the material fragments. Tissue reactions were much more pronounced when the copolymers contained more glycine units due to the fact that during the degradation process, these copolymers are more rapidly dissolved. These observations correspond with work of other authors on copolymers of $\alpha$-amino acids. ${ }^{10,11}$

When the degradation of poly(DL-lactic acid), as studied in this article is compared with poly(L-lactic acid) ${ }^{17}$ it is also observed that the lower rate of degradation of poly(L-lactic acid) is accompanied with a less severe tissue reaction. Poly(glycolic acid), which degrades even faster than poly(DL-lactic acid) showed a very severe macrophage mediated tissue response. ${ }^{9,30}$ Blood vessels were observed to grow in the direction of the implant, probably caused by the release of a macrophage angiogenic factor. ${ }^{31,32}$

The biodegradability and tissue reactions of random copoly $(\alpha$-amino acids) of L-leucine, L-aspartic acid, and L-aspartic acid esters were investigated by Marck et al. ${ }^{11}$ Nondegradable hydrophobic copolymers showed a good biocompatibility. More hydrophilic copolymers showed some degradation within 12 weeks, but the implant sites were populated by lymphocytes and plasma cells indicating antigenicity. Hydrophilic copolymers caused a temporary chemical inflammation and had disappeared within $24 \mathrm{~h}$. Appar- 
ently the rate of degradation and biocompatibility do not coincide in contrast to the polydepsipeptides described in this paper.

The in vivo degradation of poly(DL-lactic acid) has recently been studied by Visscher et al. ${ }^{18}$ The microspheres, which were intramuscularly injected in rat legs, only showed signs of macrophage infiltration from day 150 on. After 420 days poly(DL-lactic acid) fragments were still present. The tissue reaction observed was similar to our findings. Macrophages and giant cells were persisting around the implanted particles until they had completely degraded. The rate of degradation is considerably lower than that of poly(DL-lactic acid) described in this article, although the molecular weights in both studies were comparable. This discrepancy may be explained by the use of different implantation sites.

Application of these biodegradable glycine/DL-lactic acid copolymers can be expected in the field of drug release from a polymer matrix. ${ }^{19}$ The degradation time, and thus the kinetics of release, can be influenced by the composition of the copolymer.

\section{CONCLUSIONS}

The glycine/DL-lactic acid copolymers and poly(DL-lactic acid) show a comparable in vivo and in vitro degradation behavior. The degradation takes place via bulk hydrolysis of the ester bonds. Increasing the mole fraction of glycine units in the copolymer leads to a faster absorption of material, although the rate of hydrolysis is not affected by the changes in composition. The tissue reaction can be characterized as a macrophage mediated foreign body reaction. It is more severe for polymers having a higher degradation rate, i.e., for copolymers with a higher glycine content.

The authors gratefully acknowledge the assistance of I. Stokroos, J. Broere, M. P. Schakenraad-Dolfing, D. Huizinga, H. Meiborg, E. H. Blaauw, and C. Padberg. The research has been supported by the Netherlands foundation for chemical research (SON) with financial aid from the Netherlands organization for scientific research (NWO).

\section{References}

1. D. K. Gilding, "Biodegradable polymers," in Biocompatibility of Implant Materials, Vol. 2, D. F. Williams (ed.), CRC Press, Boca Raton, 1981, pp. 210-232.

2. J. Heller, "Biodegradable polymers in controlled drug delivery," CRC Crit. Rev. Ther. Drug Carrier Syst., 1, 39-90 (1984).

3. S. W. Kim, R. V. Petersen, and J. Feijen, "Polymeric drug delivery systems," in Drug Design, Vol. 10, E. J. Ariens (ed.), Academic Press, New York, 1980, pp. 193-250.

4. D. L. Wise, T. D. Fellmann, J. E. Sanderson, and R. L. Wentworth, "Lactic/glycolic acid polymers," in Drug Carriers in Biology and Medicine, G. Gregoriadis (ed.), Academic Press, New York, 1979, pp. 237-270.

5. S. J. Holland, B. J. Tighe, and P. L. Gould, "Polymers for biodegradable medical devices. 1. The potential of polyesters as controlled macromolecular release systems," J. Controlled Rel., 4, 155-180 (1986). 
6. M. J.D. Eenink, "Synthesis of biodegradable polymers and development of biodegradable hollow fibers for the controlled release of drugs," Ph.D. thesis, University of Twente, Enschede, The Netherlands (1987).

7. J. W. Leenslag, A. J. Pennings, R. R. M. Bos, F. R. Rozema, and G. Boering, "Resorbable materials of poly(L-lactide)," Biomaterials, 8, 311-314 (1987).

8. A. M. Reed and D. K. Gilding, "Biodegradable polymers for use in surgery - poly(glycolic)/poly(lactic acid) homo- and copolymers: 2 . In vitro degradation,"Polymer, 22, 494-498 (1981).

9. C.C. Chu and D.F. Williams, "The effect of $\gamma$-irradiation on the enzymatic degradation of polyglycolic acid absorbable sutures," J. Biomed. Mater. Res., 17, 1029-1040 (1983).

10. S. J. Holland, A. M. Jolly, M. Yasin, and B. J. Tighe, "Polymers for biodegradable medical devices. Hydroxybutyrate-hydroxyvalerate copolymers: hydrolytic degradation studies," Biomaterials, 8, 289-295 (1987).

11. J. M. Anderson, K. L. Spilizewski, and A. Hiltner, "Poly( $\alpha$-amino acids) as biomedical polymers," in Biocompatibility of Natural Tissues and Synthetic Analogs, D. F. Williams (ed.), CRC Press, Boca Raton, 1985, pp. 67-88.

12. K.W. Marck, R. H. Wildevuur, W. L. Sederel, A. Bantjes, and J. Feijen, "Biodegradability and tissue reaction of random copolymers of L-leucine, L-aspartic acid and L-aspartic acid esters," J. Biomed. Mater. Res., 11, 405-422 (1977).

13. K. R. Sidman, W. D. Steber, A. D. Schwope, and G. R. Schaper, "Controlled release of macromolecules and pharmaceuticals from synthetic polypeptides based on glutamic acid," Biopolymers, 22, 547-556 (1983).

14. T.N. Salthouse, "Some aspects of macrophage behavior at the implant interface," J. Biomed. Mater. Res., 18, 395-401 (1984).

15. B. F. Matlaga and T. N. Salthouse, "Ultrastructural observations of cells at the interface of a biodegradable polymer: Polyglactin 910," J. Biomed. Mater. Res., 17, 185-197 (1983).

16. R. Smith, C. Oliver, and D. F. Williams, "The enzymatic degradation of polymer in vitro," J. Biomed. Mater. Res., 21, 991-1003 (1987).

17. J. M. Schakenraad, J. A. Oosterbaan, P. Nieuwenhuis, I. Molenaar, J. Olijslager, W. Potman, M. J. D. Eenink, and J. Feijen, "Biodegradable hollow fibers for the controlled release of drugs," Biomaterials, 9, 116120 (1988).

18. G. E. Visscher, R. L. Robison, H. V. Maulding, J. W. Fong, J. E. Pearson, and G.J. Argentieri, "Note: Biodegradation of and tissue reaction to poly(DL-lactide) microcapsules," I. Biomed. Mater. Res., 20, 667-676 (1986).

19. I. Kaetsu, M. Yoshida, M. Asano, H. Yamanaka, K. Imai, H. Yuasa, T. Mashimo, K. Suzuki, R. Katakai, and M. Oya, "Biodegradable implant composites for local therapy," I. Controlled Rel., 6, 249-263 (1987).

20. D. Nissen, C. Gilon, and M. Goodman, "Polydepsipeptides, 4. Synthesis of the alternating polydepsipeptides poly(Ala-Lac) and poly(ValLac)," Makromol. Chem., Suppl., 1, 23-53 (1975).

21. R. Katakai and M. Goodman, "Polydepsipeptides. 9. Synthesis of sequential polymers containing some amino acids having polar side chains and (S)-lactic acid," Macromolecules, 15, 25-30 (1982).

22. M. Asano, M. Yoshida, I. Kaetsu, R. Katakai, K. Imai, T. Mashimo, H. Yuasa, and H. Yamanaka, "Polydepsipeptides 2," Seitai Zairyo, 4, 65-75 (1986).

23. J. Helder, J. Feijen, S. J. Lee, and S. W. Kim, "Copolymers of D, L-lactic acid and glycine," Makromol. Chem., Rapid Commun., 7, 193-198 (1986).

24. H. J. Busscher, A. W. J. Pelt, H. P. de Jong, and J. Arends, "Effect of spreading pressure on surface free energy determinations by means 
of contact angle measurements," J. Colloid Interface Sci., 95, 23-27 (1983).

25. P. O. Gerrits and L. Smid, "A new, less toxic polymerization system for the embedding of soft tissues in glycol methacrylate and subsequent preparing of serial sections," J. Microsc., 132, 81-85 (1983).

26. E. H. Blaauw, M. F. Jonkman, P. O. Gerrits, "Rapid connective tissue stain for glycol methacrylate embedded tissue," Acta Morphologica Neerlando-Scandinavica, 1988, in press.

27. J. Helder, P. Dijkstra, and J. Feijen, "In vitro degradation of glycine/ DL-lactic acid copolymers," submitted for publication.

28. C.G. Pitt and Z. Gu, "Modification of the rates of chain cleavage of poly ( $\varepsilon$-caprolactone) and related polyesters in the solid state," J. Controlled Rel., 4, 283-292 (1987).

29. C. G. Pitt, M.M. Gratzl, G.M. Kimmel, J. Surles, and A. Schindler, "Aliphatic polyesters II. The degradation of poly(DL-lactide), poly $(\varepsilon-$ caprolactone) and their copolymers in vivo " Biomaterials, 2, 215-220.

30. T. N. Salthouse and J. A. Williams, "Histological observation of enzyme activity at suture implant sites," J. Surg. Res., 9, 481 (1969).

31. N. P. Ziats, K. M. Miller, and J. M. Anderson, "In vitro and in vizo interactions of cells with biomaterials," Biomaterials, 9, 5-13 (1988).

32. C.F. Nathan, H.W. Murray, and Z.A. Cahn, "The macrophage as an effector cell," N. Engl. J. Med., 303, 622 (1980).

Received August 16, 1988

Accepted March 7, 1989 